\title{
College Physics Teaching Model Design and Evaluation Research of Students' Seriousness
}

\author{
Hongzhi Zhao ${ }^{*}$ \\ College of Physics and Electronic Engineering, Xinxiang University, Xinxiang 453003, Henan, China
}

\begin{abstract}
: this paper studies the physics teaching model design for college students, takes students' seriousness as a criterion, and explores whether using the physics model is conductive to helping students learn seriously. To take hopfield as an example, the paper elaborates the teaching model design process in detail. After receiving the investigation feedback from students, students' acceptance of the teaching model and the teaching effectiveness are embodied, and the rational physics teaching method of college students is analyzed. Further, the final examination results are received from students for objective feedback, in order to explore the proper teaching methods.
\end{abstract}

Keywords: College physics, seriousness, teaching model.

\section{BACKGROUND}

In a majority of engineering disciplines, college physics is often taught as a basic subject, and even some liberal arts students in institutions of higher education sponsored by Project 985 are studying physics. It is thus clear that in China's university education, college physics plays a selfevident role. Through integration of various scholars, and many years of teaching experience, college physics has become a mature discipline and an irreplaceable scientific education course in discipline construction [1-5]. In contemporary college courses, the knowledge system of college physics is relatively complete; every independent chapter can be stretched and every little problem deserves careful study. When professors teach the college physics course, they often reasonably quote the cutting-edge research into daily teaching, or expand a chapter in college physics in the form of elective courses for detail explanation. All of the above examples show college physics has extensibility and vitality as a discipline. For physics teaching, obvious effects can be achieved by using the penetrating education method; when professors teach the physics course, they can expand the teaching content appropriately. This method can effectively improve students' level of understanding and knowledge about the course. For example, submillimeter's research work can be integrated into college physics teaching suitably. It is believed that this can get satisfactory results [6-8]. The main point of this paper is to combine the teaching model into college physics teaching, enhance students' learning enthusiasm by using the suitable physics model, and enhance students' learning seriousness. In addition, this way can be used for research and assessment.

\section{METHOD}

Teachers should adhere to the teaching focus in teaching activities, rationally make use of the relationship between different disciplines, and use the transfer law for teaching design. Teaching shifting usually means to transfer the learning impact of one kind of knowledge to another. In teacher's teaching applications, the transfer law is always seen as an effective teaching approach, and teachers often evaluate students' ability to learn through the transfer law. In this paper, the knowledge transfer used herein represents the positive transfer of learning and exerts a positive impact on learning. Reasonable transfer can effectively improve students' understanding efficiency and level of knowledge. Students can find the same point in new and old courses for the transfer of knowledge, and on the basis of the existing knowledge, they can develop new understandings of the new knowledge. In this way, students can easily understand the new knowledge and consolidate the old knowledge. Using the transfer law can apply specific physics concepts, and the teaching model may also be reasonably transferred. By transferring physics knowledge, the design flow is obtained as shown in Fig. (1).

\section{MODEL DESIGN}

\subsection{Model Review}

The Hopfield neural network model is taken as an example. First of all, the course teaching begins with reviewing the physics models and research methods. Students who study this problem have had a preliminary understanding of physics learning. At the start of the course, the mechanics chapters 1-4 are reviewed first as well as Newton's kinematics. Again electromagnetism chapters 5-8 are reviewed, including the charge space structure in one-dimensional, twodimensional, three-dimensional spaces, etc. Advanced mathematics method is used for segmentation, and the total charge carried of the charge distribution area is acquired: $\mathrm{Q}=\int \eta d l ; \mathrm{Q}=\int \sigma d S ; \mathrm{Q}=\int \rho d \mathrm{~V}$. After formula computing, the conclusion is proved accurate [6]. 


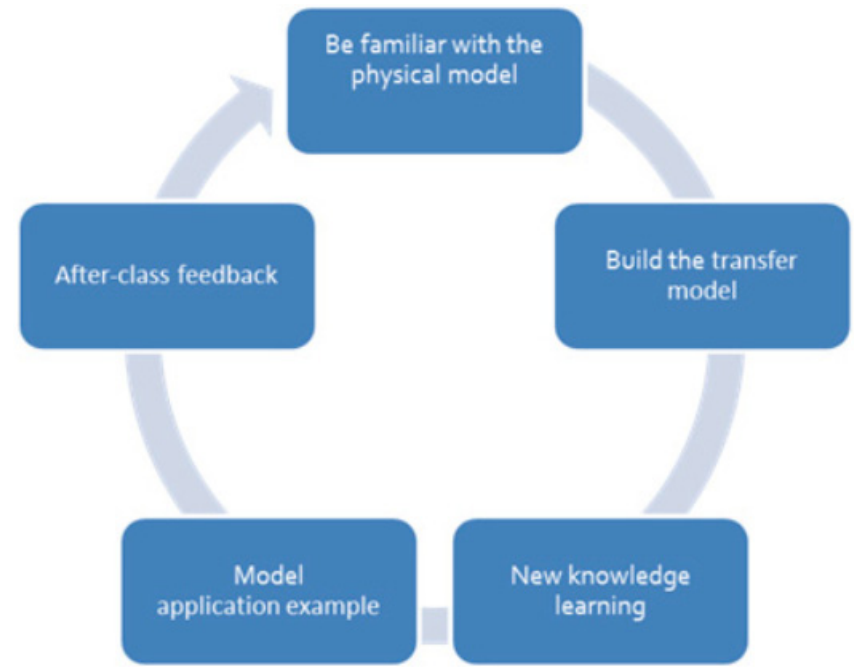

Fig. (1). Learning Flow Chart of the Physics Model.

This shows that the method of applying advanced mathematics to analyze college physics is reasonable and has clear logic. Moreover, the conclusion of this study is not the knowledge review lesson, but results obtained from teaching research. Teachers should pay attention to clearly explaining the knowledge points during the teaching course. If student feel confused about it, if time permitted, they can review the knowledge that has been explained previously and let students make a summary by themselves with the assistance of others chapters. Teachers should prioritize the knowledge points during teaching. Due to limited time, teachers cannot teach every knowledge point to students in detail, and they have to carry out an accurate assessment of the course time. They can explain more important knowledge points in detail and less important ones roughly, and do not mention or basically mention unimportant parts or those uninvolved in the syllabus.

\subsection{Modeling}

As for modeling, knowledge is required to filter first, removing the secondary factors and retaining its core features. In the design of neurons, two states of neurons should be taken into account, which are the suppressed state and the activated state. These two states can record the neurons. Activated neurons are denoted as +1 , and -1 for suppressed neurons; neuronal structure and impulsion and other complex responses are left unrecorded $[9,10]$. The model record simplifies neuron to two cases: one is import and the other is output. Students' thinking should be abstract and the physics model is built. The connection strength conducted by connections between neurons is T. The neuron model is shown in Fig. (2).

If neurons are connected to each other, every two neurons interact with each other. The interaction between neuron $\mathrm{i}$ and other neurons is denoted as $\mathrm{K}_{\mathrm{i}}$ :

The signal transmission between neurons can be expressed as the following functions:

After teaching students the physics image in the neurons model and requiring them to master it, the neural network model can be introduced, and the model used herein is the hopfield model.

Provided there are $n$ neurons, there are interactions between neurons, and the interaction between them is represented in a matrix form, which is called the connection matrix, denoted as T. The matrix form is as follows:

The neural network model is built, and this construction method has a common application scope.

\subsection{Properties of the Biological Neural Network Model}

After the neural network model is stimulated by external factors, it will also consume some time. Suppose time $t$ is included in the network neuronal signaling and responds to $\mathrm{xi}$, the state is shown in the following equation:

\section{AFTER-CLASS FEEDBACK AND SURVEY}

The physics teaching classes in our school are randomly chosen to implement this teaching method. After one semester, a questionnaire survey is conducted among students receiving this method and students from other classes. It is found that $79 \%$ of students who receive this method approve the teaching process of this teaching method, thinking that what the teacher explains can be quickly absorbed and applied; $40 \%$ of the students expect to improve the test scores; $59 \%$ of students feel that they have improved knowledge, and think this teaching method is novel and attractive. Among students who haven't received this way of teaching, $32 \%$ of them express wishes to be taught in this way. After the survey, it is found that this method is popular among students and gets recognition from most of them. It is con-

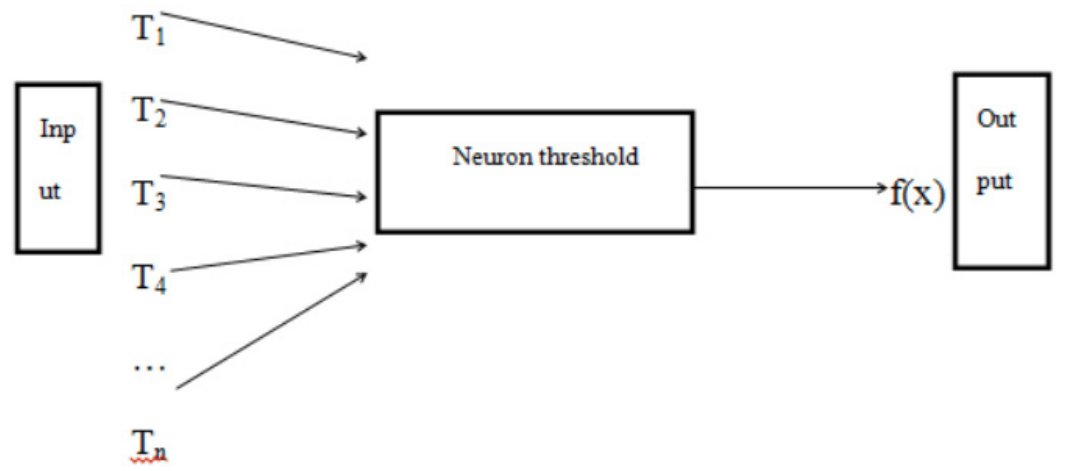

Fig. (2). Neuron model. 
ductive to expanding the subject knowledge. Besides, a survey conducted among some students not majoring in physics shows that non-physics majors find the usefulness of physics, and even some students say they are considering pursuing a master's degree in physics. The questionnaire also involves students' initiative learning of new knowledge. As is shown, $52 \%$ of the students think teachers rarely develop new knowledge in their daily teaching and they have the intention to accept new knowledge.

\section{PHYSICS TEACHING DESIGN PRINCIPLES}

Classroom education is a serious matter and physics education is no exception. Classroom education is a combination of teaching and learning, with the main purpose of ensuring the smoothness of the classroom education process, during which students get on very well with teachers; the teaching effect is obvious and students gain significant achievements. However, the conventional classroom education does not have an ideal effect on students, and many students think conventional education boring and the physics theories difficult to understand. For them, much knowledge learnt gives them a fuzzy feeling. College physics learning is difficult for students, and therefore, it is particularly important to visualize and concretize physics knowledge. Reasonable and reliable teaching methods enable to intuitively display new knowledge to students, and using the teaching model can also visualize the abstract physics knowledge and change the tedious physics theories to be easier to understand. The most critical is that the physics model will be introduced at the appropriate timing during the teaching process, which is in line with the psychology of students.

This paper makes an investigation into the effect of using physics models in college physics, with the main entry point of the physics knowledge involved in college physics classes. The teaching material is the fifth edition of the physics textbook, and the reason for selecting this version is that every knowledge point in the textbook is logic and displays in the physics model. And the basic model is the key knowledge point of each chapter, with the overall arrangement highlighting the main knowledge and physics models. In the daily learning, students can directly and clearly link the whole idea of teaching materials. Therefore, it is also very appropriate to use the physic models to explain the expansion class. Meanwhile, physics teaching is usually tedious. If students are not interested in physics courses, they would not be actively involved in the educational process, and the course content is extremely abstract, which also needs the introduction of teaching models. The model itself has intuitively explained the physics content and also integrated the scientific research methods. On the other hand, the physics research is to describe the abstract model of experience and practice, to detect law in practice and summarize it into a formula or experience. After drawing a conclusion, with standardized and idealized analysis, the physics research can be concluded and promoted under an ideal model. Physics has also played an important role in training students' thinking ability. After learning college physics, students get imperceptible training of the scientific way of thinking, and gradually develop the generalization ability and abstract thinking. After making summaries for several times, students can develop creativity and independent thinking.

\section{CONCLUSION}

This teaching method is conductive to effectively improving students' learning efficiency and teachers' teaching speed. According to practice, this way of teaching can help students improve the overall performance and enhance their learning enthusiasm. Moreover, students using this method to study rarely slack off in their studies when teachers explain not important knowledge points. In physics education, expansion of new knowledge and model design has positive impacts on physics teaching. Designing the physics teaching model and using the knowledge transfer approach help integrate the old and the new physics knowledge, and benefit students' research concepts and scientific learning. It provides students with easy access to the cutting-edge scientific research field, so that students can apply new knowledge in practice. Through classroom education, students can have a new awareness and understanding of new knowledge. Under the guidance of teachers, students can summarize and expand the physics knowledge by themselves.

The design of college physics teaching model helps improve the teaching efficiency of teachers and effectively enhance the learning quality of students. Further, it contributes to the use of physics discipline in the field of science. In China, there is still a lack of the teaching model design. This way is often used in teaching senior undergraduate and junior postgraduate in foreign science colleges. The physics education model is not commonly used and in existing teaching system and capital, it is also difficult to comprehensively apply it, but its effect cannot be underestimated. It is worth trying in physics teaching. Through the survey of students, it can also be found that the effect of this method is so obvious that can gain effective feedback from student's education. It is worth promoting and applying in education of physics.

\section{CONFLICT OF INTEREST}

The author confirms that this article content has no conflict of interest.

\section{ACKNOWLEDGEMENTS}

Declared none.

\section{REFERENCES}

[1] R. Driver, N. Paul and O. Jonathan, "Establishing the norms of scientific argumentation in classrooms," Science Education, vol. 84 , no. 3, pp. 287-312, 2000.

[2] W. H. Bingle, and P. J. Gaskell, "Scientific literacy for decisionmaking and the social construction of scientific knowledge," Science Education, vol. 78, no. 2, pp. 185-201, 1994.

[3] C. Macleod, "Teenage pregnancy and the construction of adolescence scientific literature in South Africa," Childhood, vol. 10, no. 4, pp. 419-437, 2003.

[4] M. T. Battista, "The mathematical miseducation of america's youth: ignoring research and scientific study in education," Phi Delta Kappan, vol. 80, no. 6, pp. 425-433, 1999, Note: This article contains 2 figures that cannot be reproduced in text-only format. Please see a print copy of the article. Copyright Notice Phi Delta Kappa International, Inc., holds copyright to this article, which may be reproduced or otherwise used only in." Education 80.6 (1999): 425-433.

[5] M. Larochelle, and D. Jacques, "Of course, it's just obvious': adolescents' ideas of scientific knowledge," International Journal of Science Education, vol. 13, no. 4, pp. 373-389, 1991. 
[6] I. A. Halloun, and D. Hestenes, "The initial knowledge state of college physics students," American Journal of Physics, vol. 53, no. 11, pp. 1043-1055, 1985.

[7] B. David, and E. Eugenia, "College physics students' epistemological self-reflection and its relationship to conceptual learning," American Journal of Physics, vol. 70, no. 12, pp. 1249-1258, 2002.

[8] R. J. Dufresne, et al., "Classtalk: A classroom communication system for active learning," Journal of Computing in Higher Education, vol. 7, no. 2, pp. 3-47, 1996
[9] W. Sun, S. T. Xue, and N. Ma, "Fault diagnosis of relay protection device based on fuzzy Bp neutral network model," Conference Anthology, IEEE. IEEE, 2013.

[10] H. Chen, Y. Zhao, J. Lin, and M. Guo, "A method of gear defect intelligent detection based on transmission noise," International Symposium on Precision Engineering Measurement and Instrumentation. International Society for Optics and Photonics, 2015.

Received: June 10, 2015

(C) Hongzhi Zhao; Licensee Bentham Open.

This is an open access article licensed under the terms of the Creative Commons Attribution Non-Commercial License (http://creativecommons.org/licenses/by-nc/3.0/) which permits unrestricted, non-commercial use, distribution and reproduction in any medium, provided the work is properly cited. 